\title{
Inter-study variability in CMR measurements of right ventricular volume, mass and ejection fraction in tetralogy of fallot: a prospective observational study
}

\author{
Shannon E Blalock ${ }^{1,2}$, Puja Banka ${ }^{1,2}$, Tal Geva ${ }^{1,2}$, Andrew J Powell ${ }^{1,2}$, Jing Zhou' ${ }^{1}$, Ashwin Prakash ${ }^{1,2^{*}}$ \\ From 15th Annual SCMR Scientific Sessions \\ Orlando, FL, USA. 2-5 February 2012
}

\section{Background}

Cardiac MRI (CMR) is commonly used for serial monitoring of right ventricular (RV) size and function in patients with repaired tetralogy of Fallot (TOF). However, the inter-study variability of these measurements is not known, which hinders accurate interpretation of serial changes. In this study we prospectively assessed the inter-study variability of CMR measurements of RV size and function in TOF patients.

\section{Methods}

Patients with repaired TOF referred for a clinically indicated CMR examination at our institution were prospectively enrolled. ECG-gated steady-state free precession cine imaging of ventricular long- and short-axis planes was obtained on a $1.5 \mathrm{~T}$ scanner. Immediately after the conclusion of the examination, patients returned for a second study performed by a different technologist. Ventricular size and function data from both short-axis image sets were analyzed by a single observer and compared using Bland-Altman analysis with calculation of a repeatability coefficient (2SD of difference between studies), and intra-class correlation coefficient (ICC).

\section{Results}

Between March 2009 and April 2010, 30 patients with repaired TOF (median age 23.5 years, $53 \%$ male) were enrolled. Mean RV end-diastolic volume was 158.1 \pm 48

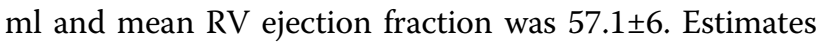
of repeatability coefficient and ICC are summarized in

'Department of Cardiology, Children's Hospital Boston, Boston, MA, USA Full list of author information is available at the end of the article the table. CMR measurements were highly reproducible between studies for quantification of RV end-diastolic volume (repeatability coefficient $24.1 \mathrm{ml}$, ICC 0.99 ), ejection fraction (repeatability coefficient $5.8 \%$, ICC 0.94 ), and mass (repeatability coefficient $9.7 \mathrm{~g}$, ICC 0.93). ICC values were not different between RV and LV for most parameters except mass, for which they were higher for the LV (0.99 vs $0.93, p=0.004)$. ICC values for all the CMR parameters were not influenced by the presence of a transannular patch.

\section{Conclusions}

CMR measurements of RV and LV size and function in repaired TOF patients are highly reproducible between studies. These data will aid in interpretation of serial changes and may be useful for sample size calculation in clinical trials.

\section{Funding}

None.

Author details

'Department of Cardiology, Children's Hospital Boston, Boston, MA, USA. 2Department of Pediatrics, Harvard Medical School, Boston, MA, USA.

Published: 1 February 2012

doi:10.1186/1532-429X-14-S1-P104

Cite this article as: Blalock et al.: Inter-study variability in CMR

measurements of right ventricular volume, mass and ejection fraction in tetralogy of fallot: a prospective observational study. Journal of Cardiovascular Magnetic Resonance 2012 14(Suppl 1):P104. 
Table 1 Inter-study variability in CMR measurements

\begin{tabular}{|c|c|c|c|c|c|}
\hline & \multicolumn{2}{|l|}{ LV } & \multicolumn{2}{|l|}{ RV } & \multirow{2}{*}{$\begin{array}{c}\mathrm{p} \text { value comparing ICC } \\
\text { between LV/RV }\end{array}$} \\
\hline & $\begin{array}{c}\text { Repeatability (2SD of } \\
\text { difference between studies) }\end{array}$ & $\begin{array}{l}\text { Intra-class } \\
\text { correlation } \\
\text { coefficient }\end{array}$ & $\begin{array}{l}\text { Repeatability (2SD of } \\
\text { difference between studies) }\end{array}$ & $\begin{array}{l}\text { Intra-class } \\
\text { correlation } \\
\text { coefficient }\end{array}$ & \\
\hline $\begin{array}{l}\text { End-diastolic } \\
\text { volume }\end{array}$ & $17.2 \mathrm{ml}$ & 0.98 & $24.1 \mathrm{ml}$ & 0.99 & 0.8 \\
\hline $\begin{array}{l}\text { End-systolic } \\
\text { volume }\end{array}$ & $12.3 \mathrm{ml}$ & 0.98 & $17.7 \mathrm{ml}$ & 0.98 & 0.7 \\
\hline $\begin{array}{l}\text { Stroke } \\
\text { volume }\end{array}$ & $17.0 \mathrm{ml}$ & 0.93 & $21.9 \mathrm{ml}$ & 0.95 & 0.65 \\
\hline $\begin{array}{l}\text { Ejection } \\
\text { fraction }\end{array}$ & $6.6 \%$ & 0.84 & $5.8 \%$ & 0.94 & 0.07 \\
\hline Mass & $11.6 \mathrm{~g}$ & 0.99 & $9.7 \mathrm{~g}$ & 0.93 & 0.004 \\
\hline
\end{tabular}

ICC=intra-class correlation coefficient, $\mathrm{SD}=$ standard deviation. 